(c) American Dairy Science Association, 2004.

\title{
Factors Affecting Calcium Lactate and Liquid Expulsion Defects in Cheddar Cheese
}

\author{
P. A. Swearingen, D. E. Adams, and T. L. Lensmire \\ Land O'Lakes, Inc., Arden Hills, MN 55164
}

\section{ABSTRACT}

This paper summarizes the results of 2 studies designed to investigate the influence of several manufacturing and curing treatments on the appearance of Cheddar cheese defects. Specifically, 2 defects, calcium lactate crystal formation and the expulsion of free liquid (weeping) were monitored in Cheddar cheese. Both studies were conducted at a commercial cheese manufacturing facility that produces Cheddar in $18.14-\mathrm{kg}$ (40-lb) blocks. In the first study we monitored cheese calcium, both total and soluble during manufacture and early curing. In the second study we measured cheese $\mathrm{pH}$ from $3 \mathrm{~d}$ through $8 \mathrm{mo}$, as well as some factors that are influenced by cheese $\mathrm{pH}$. Early cheese $\mathrm{pH}$ ( $3 \mathrm{~d}$ to $7 \mathrm{~d}$ ) patterns were used to select vats of cheese for retail packaging. Mild Cheddar packaged at $30 \mathrm{~d}$ postmanufacture and sharp Cheddar packaged at $8 \mathrm{mo}$ postmanufacture from the same vats were monitored for the incidence and severity of the defects. Our results indicated that factors measured in early stages of manufacture and curing (less than $7 \mathrm{~d}$ ) such as cheese $\mathrm{pH}$ at mill, lactic acid concentration, nonprotein nitrogen, and calcium (total and soluble) in cheese did not correlate with the appearance of either calcium lactate or expulsion of free liquid in packaged cheeses. Factors including $\mathrm{pH}$, lactic acid concentrations, and soluble calcium measured during curing (greater than $7 \mathrm{~d}$ ) of cheese were found to be statistically significant in the development of defects and appeared to be associated with use of specific starter culture groups. In the study, 5 different starter culture groups, each consisting of a 4-strain blend of Lactococcus lactis ssp. cremoris and Lactococcus lactis ssp. lactis, were used to manufacture the cheeses. Cheese manufactured with one particular culture group showed no incidence of calcium lactate crystal formation or weeping during curing and shelf-life of cheeses in this study. This starter group also generated the least amount of $\mathrm{pH}$

Received May 2, 2003.

Accepted September 5, 2003.

Corresponding author: P. A. Swearingen; e-mail: PASwearingen@ landolakes.com.

change in cheese during the first month of curing. From these results we conclude that starter culture group, more than any other factor measured, played an important role in the development of calcium lactate and liquid expulsion defects in Cheddar cheese. Starter culture group appeared to strongly influence cheese $\mathrm{pH}$, lactic acid, and soluble calcium concentrations during curing and storage.

(Key words: calcium lactate, liquid expulsion, starter culture, Cheddar cheese)

Abbreviation key: $\mathbf{S} / \mathbf{M}=$ salt in moisture.

\section{INTRODUCTION}

Calcium lactate crystal formation is a defect commonly found in Cheddar and other varieties of cheese. This defect appears as white spots or crystals on the surface of cheese and is often confused with mold growth by consumers. While calcium lactate on cheese is not harmful to the consumer, it is perceived as a quality defect and can generate consumer complaints.

The development of calcium lactate crystals on Cheddar cheese have been shown to be influenced by several factors (Pierce et al., 1973). Concentrations of calcium and lactate ions existing in cheese serum are very close to saturation and small increases in the concentration of either component could result in super saturation and crystallization. It is also theorized that milk citrate levels and the subsequent utilization of citrate by microorganisms may play a role in calcium lactate formation. Curd washing, curing, and storage temperature are also sited as other potential contributors to the defect. Morris et al. (1988) substantiated some of this information by defining that crystals were formed at a single nucleation site when concentration limits were reached.

More recent published work in this area (Thomas and Crow, 1983; Dybing et al., 1988; Johnson et al., 1990) also suggests that calcium lactate is formed when $\mathrm{L}(+)$-lactate is converted into a racemic mixture of $\mathrm{L}(+)$ - and $\mathrm{D}(-)$-lactate, the latter being much more prone to crystallization. The conversion of $\mathrm{L}(+)$-lactate to $\mathrm{D}(-)$-lactate is thought to be carried out by certain strains of lactobacilli and pediococci that are intro- 
duced into the cheese through cheese-milk and manufacturing.

The standard corrective actions to retard or prevent calcium lactate crystal formation on cheese has been to: 1) reduce the concentration of lactic acid in finished cheese, 2) reduce or eliminate undesirable lactobacilli or pediococci populations from the cheese manufacture process, 3) control storage temperature, and 4) vacuum package the cheese to minimize the airspace around the outer cheese surface where crystal formation takes place (Dybing et al., 1988; Olson and Johnson, 1989; Johnson et al., 1990; Johnson et al. 1990). Even when all of the above recommendations are incorporated into the manufacturing procedures for Cheddar cheese, calcium lactate crystal formation can still occur. This suggests another mechanism is involved in the development of the crystals.

Cheddar cheese is a matrix consisting of paracasein (in the form of a calcium-paracaseinate-calcium phosphate-complex), fat, water, lactic acid, minerals, and salt (sodium chloride). Physical-chemical properties of the paracasein such as water binding capacity and swelling are greatly affected by $\mathrm{pH}$ or acid level in cheese. Substantial work with mozzarella cheese (Guo et al., 1997; Kindstedt and Guo, 1998) has shown that cheese $\mathrm{pH}$ during manufacture and curing is vital to performance characteristics of that cheese. Their work has shown that as cheese $\mathrm{pH}$ is lowered, cheese calcium moves from the colloidal state (calcium paracaseinate-phosphate complex) to a soluble state (in serum). Increasing $\mathrm{pH}$ causes this reaction to reverse. Work by these and other researchers have also shown that as the calcium moves from the colloidal state to soluble state solubilization of paracasein occurs (Czulak et al., 1969; Guo et al, 1997; Curley et al., 1998). This process transforms cheese from a tough, rubbery, squeaky curd to a smooth, creamy, softer cheese.

In our studies, the influence of $\mathrm{pH}$ during manufacture and curing of Cheddar cheese was evaluated to understand its effects on the development of defects, including calcium lactate crystals and expulsion of free liquid from cheese in the retail package, a defect commonly referred to as weeping or wet. The cheese used in this study was manufactured commercially rather than in a pilot facility in order to better understand and define these 2 cheese defects and their incidence as they occur on a commercial scale.

\section{MATERIALS AND METHODS}

\section{Cheese Manufacturing, Sampling, Testing, and Packaging}

Cheddar cheese was made at a commercial cheese plant in the United States. Cheese was make according
Table 1. Starter cultures used in cheese manufacture.

\begin{tabular}{ll}
$\begin{array}{l}\text { Starter } \\
\text { culture } \\
\text { group }\end{array}$ & $\begin{array}{l}\text { Strains contained in each } \\
\text { starter culture group }\end{array}$ \\
\hline 1 & Lactococcus lactis ssp. cremoris (3 strains) \\
& L. lactis ssp. lactis (1 strain) \\
2 & L. lactis ssp. cremoris (4 strains) \\
3 & L. lactis ssp. cremoris (4 strains) \\
4 & L. lactis ssp. cremoris (3 strains) \\
& L. lactis ssp. lactis (1 strain) \\
5 & L. lactis ssp. cremoris (4 strains) \\
\hline
\end{tabular}

${ }^{1}$ Four strains per starter group.

to standard Cheddar cheese making procedures utilizing Double $\mathrm{O}$ vats (Damrow Inc., Fond Du Lac, WI), filled with approximately $22,730 \mathrm{~kg}(50,000 \mathrm{lb})$ of HTST-pasteurized $\left(72^{\circ} \mathrm{C}\right.$; $\left.15 \mathrm{~s}\right)$ whole milk. No modifications to cheese-make parameters occurred during the course of this study. Five different, commercially available, mixed mesophilic culture blends were utilized during manufacture. The blends were combinations of Lactococcus lactis ssp. cremoris and L. lactis ssp. lactis strains (Table 1). Starter was grown in external $\mathrm{pH}$ control starter media in bulk starter tanks. The inoculation target was $10^{6}$ to $10^{7} \mathrm{cfu} / \mathrm{mL}$ in cheese milk to assure proper fermentation of lactose.

Annatto (Chr. Hansen's Lab., Inc., Milwaukee, WI) and a 35\% calcium chloride (Chr. Hansen's Lab., Inc., Milwaukee, WI) solutions were added to milk per manufacturer's recommendation. Milk was coagulated using double strength chymosin (Chymax II 500, Chr. Hansen's Lab., Inc., Milwaukee, WI) and the coagulation process occurred over a 30 -min time period at 31.1 to $32.2^{\circ} \mathrm{C}\left(88\right.$ to $\left.90^{\circ} \mathrm{F}\right)$. The mixture was then cooked to 38.3 to $38.9^{\circ} \mathrm{C}\left(101\right.$ to $\left.102^{\circ} \mathrm{F}\right)$ in approximately 30 min under constant agitation. Curds and whey were transferred to a draining matting conveyor belt (Damrow, Inc., Fond Du Lac, WI) for cheese mat formation and completion of the fermentation. The cheese mat was subsequently milled and salted. Cheese blocks containing approximately $18.14 \mathrm{~kg}(40 \mathrm{lb})$ of cheese were produced by using a block forming tower (Stoelting, Kiel, WI). Cheese blocks were sealed in plastic bags and placed into $18.14 \mathrm{~kg}(40 \mathrm{lb})$ corrugated, lined cheese boxes, and allowed to cure under refrigerated temperatures [less than $\left.7^{\circ} \mathrm{C}\left(45^{\circ} \mathrm{F}\right)\right]$.

In our initial study, 4 vats of commercially manufactured Cheddar cheese were evaluated during early curing for $\mathrm{pH}$ and soluble and total calcium content. All vats were manufactured with the same starter culture group. Cheese curd was analyzed throughout the cheese-make, specifically at cook, pump-over, mill, block formation, 0.75 (18 h), 1, 7, 28, and $90 \mathrm{~d}$. At cook and pump-over, the curd from each vat was sampled 
and drained, and a water extraction was performed immediately following draining. The filtrate was frozen and tested at a later time using the method described in the cheese chemistry section of this paper.

In the second study, blocks from 97 Cheddar cheese vats were sampled during curing at $3,7,14,21,28$, $42 \mathrm{~d}$ and at $3,4,5,6,7$, and 8 mo. A 30- to 35-g cheese sample was taken from Cheddar blocks using a Cheddar cheese block trier, model $8 \mathrm{M}$ (Nelson-Jameson cat. no. 439-2005). To understand the effect of $\mathrm{pH}$ changes within the first week postmanufacture on appearance of calcium lactate and weeping defects during curing and shelf life, cheese was then selected based upon $\mathrm{pH}$ the change (increase or decrease [2 levels studied] from 3 to $7 \mathrm{~d}$ ) to participate in a packaging and shelf-life study (Table 2). A total of 20 vats of cheese were selected and converted into packaged retail chunks and monitored for calcium lactate crystal formation and weeping defect in cheese throughout its shelf life.

Cheese blocks (18.14 $\mathrm{kg}$ or $40 \mathrm{lb}$ ) from each of the 20 vats were converted to $228-\mathrm{g}$ (8-oz) cuts and sealed in Hayssen packaging between 30 and $60 \mathrm{~d}$ postmanufacture, and these were designated as mild Cheddar. At 8 to 9 mo, 18.14-kg (40-lb) blocks from the same vats were converted to 228 -g (8-oz) chunks and packaged as sharp Cheddar. Retail packaged cheese was stored for its full shelf life $(6 \mathrm{mo})$ at $4^{\circ} \mathrm{C}\left(40^{\circ} \mathrm{F}\right)$. All packaged cheese produced from each 18.14 -kg (40-lb) block was examined for the presence or absence of the calcium lactate and free liquid (weeping) defect throughout storage and at the end of the product shelf life. Cheese defect results were recorded as positive if either calcium lactate and/or free liquid (weeping) were observed by visual examination. Weeping defect was characterized as a clear liquid observed in the 228g (8-oz) package between the cheese chunk and the packaging film. Levels varied from a few droplets along creases in the package to approximately $1 \mathrm{~mL}$ along the bottom edge of the chunk. The defects appeared to be interrelated and were difficult to separate because cheese that exhibited weeping may eventually show only calcium lactate crystals or a combination of the 2 defects. Varying degrees of the defect were noted, but defect levels had to be substantial enough to warrant a consumer complaint to be recorded as a positive.

A paired $t$-test was used to determine whether the differences between sample populations (groups with and without the appearance of defect) were significant. Significance was determined at $P<0.05$. Statistical analysis by $t$-test was performed using Microsoft Excel version 2002 .

\section{Cheese Chemistry}

Cheese was examined for chemical composition including protein, fat, moisture, $\mathrm{pH}$, and salt at $3 \mathrm{~d}$ postmanufacture. Protein and fat analysis were determined using Macro-Kjeldahl $(\mathrm{N} \times 6.38)$ and Babcock methods (10). Cheese moistures were determined using a drying oven $\left(102^{\circ} \mathrm{C}: \mathrm{IDF}, 1982\right)$. Salt content was determined with a Corning Chloride Analyzer 926 (Corning, Medfield, MA). Cheese $\mathrm{pH}$ was measured with a Corning general-purpose combination electrode at ambient temperature.

Lactic acid and NPN were measured in cheese at 1 mo postmanufacture and at the end of the shelf-life study. $\mathrm{D}(-)-$ and $\mathrm{L}(+)$ - Lactic acid content in cheese was measured using a colorimetric method (Boehringer Mannheim Biochemical, Indianapolis, IN) . The NPN method (AOAC International, 9991.21) was based on a $24 \%$ TCA precipitation of large and medium molecular weight peptides allowing for the measurement of small, soluble peptides and amino acids collected as a filtrate.

The total calcium content in cheeses was determined by atomic absorption spectrophotometry (12) during cheese manufacture and at 1 mo postmanufacture.

Soluble calcium was measured in cheese at $1 \mathrm{mo}$ postmanufacture and at the beginning and end of the shelf-life studies. Samples for soluble calcium were prepared according to the method described by Kindstedt and Guo (1998). Modifications to their method were as follows: Water-extracts were prepared for all cheeses in the shelf life study at specified time intervals (beginning and end of shelf-life). Grated cheese $(10 \mathrm{~g})$ was mixed with $90 \mathrm{~mL}$ of deionized ambient water in an Osterizer Blender, model 6630 (Sunbeam Corporation) for $60 \mathrm{~s}$ on high speed. The mixture was immediately filtered through Whatman \#4 paper. The filtrate was collected and analyzed by atomic absorption spectrophotometry to determine soluble calcium content.

\section{RESULTS AND DISCUSSION}

\section{Calcium Profile in Cheddar During Manufacture}

In our initial study, $\mathrm{pH}$ and soluble and total calcium were measured during manufacture and curing through 90 d. This data is illustrated in Figure 1, with each data point representing an average of 4 vats of cheese. The results of this study defined the need for additional test parameters in the second study where starter culture groups, lactic acid, and salt were also evaluated.

As expected, soluble calcium appears to readily diffuse from curd to whey during wet acid development in 


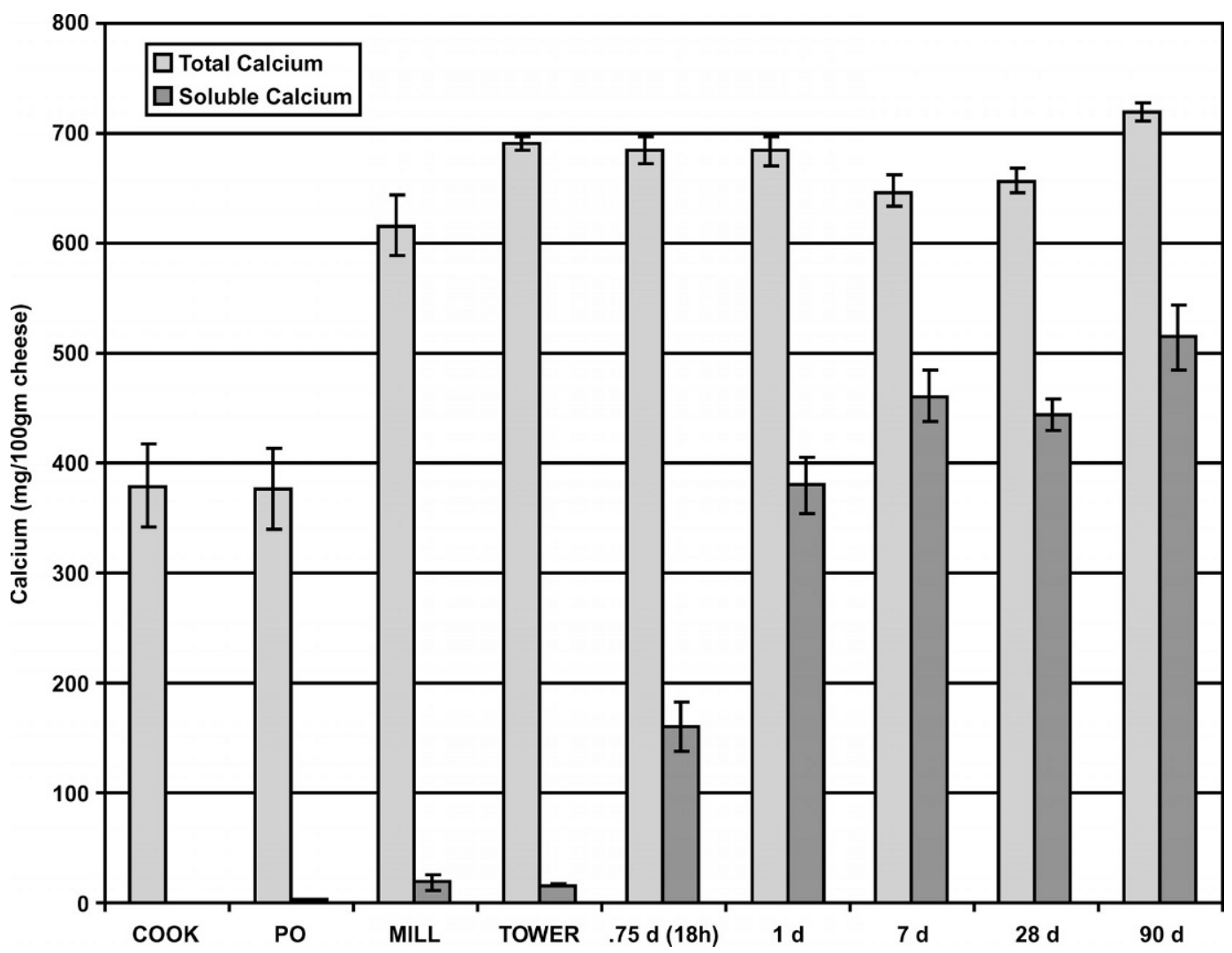

Figure 1. Calcium in cheese during manufacture and curing through 90 d. Each point is the average of 4 different cheese vats. Error bars represent one standard deviation from the average value.

Cheddar manufacture (i.e., cook through pump-over). The data shows that soluble calcium remains below 5 mg per $100 \mathrm{~g}$ of cheese, or less than $1.5 \%$ of the total calcium in cheese through pump-over. At exit from block forming towers, the level of soluble calcium had begun to increase to $18.75 \mathrm{mg} / 100 \mathrm{~g}$ of cheese (average cheese $\mathrm{pH}$ was 5.33). By $18 \mathrm{~h}$, soluble calcium levels in cheese were at $162 \mathrm{mg} / 100 \mathrm{~g}$ of cheese or approximately $23.4 \%$ of the total calcium. And by $24 \mathrm{~h}$, soluble calcium was $379 \mathrm{mg} / 100 \mathrm{~g}$ of cheese (average cheese $\mathrm{pH}$ was 5.21). Soluble calcium continued to increase through $7 \mathrm{~d}$, at which point it accounted for more than $65 \%$ of the total calcium in cheese (Figure 1). The average cheese $\mathrm{pH}$ was 5.01 at $7 \mathrm{~d}$. After $7 \mathrm{~d}$, soluble calcium levels changed very little through 3 mo, correlating well with little or no cheese $\mathrm{pH}$ change during that time. This is consistent with the work of Guo et al. (1997) that showed $\mathrm{pH}$ strongly influenced calciumparacaseinate-complex causing calcium to move from the colloidal state to the soluble state (in serum) in cheese.

\section{pH Profile in Cheddar During Curing}

The $\mathrm{pH}$ of cheese was studied in order to understand the typical cheese $\mathrm{pH}$ pattern during curing for this manufacturing facility. Each of the 97 cheeses was evaluated for $\mathrm{pH}$ over $8 \mathrm{mo}$. At this particular facility, on average, cheese $\mathrm{pH}$ decreases from day of make and through early curing (less than one month). Figure 2 depicts the results of the $\mathrm{pH}$ assessment sorted by starter group used for the manufacture of the cheeses during this time period. On average, one starter culture blend (group 3) demonstrated a unique $\mathrm{pH}$ profile over the first month of curing compared with the other 4 starter culture blends used in this study. The $\mathrm{pH}$ pattern of group 3 , differed from the others in that the rate of $\mathrm{pH}$ change slowed and the $\mathrm{pH}$ began to rise by the end of the first month. The other 4 culture blends were more dramatic in rate of cheese $\mathrm{pH}$ changes over the first month.

\section{Shelf Life of Cheddar in Retail Package}

Table 2 shows the calcium lactate and weeping defect rate, as a percentage, observed in packaged cheeses at the end of shelf life by production day and vat. Varying levels of calcium lactate or weeping defects were apparent by the end of the retail shelf life of the cheese. These results showed that the $\mathrm{pH}$ change from 3 to $7 \mathrm{~d}$ had little affect on the presence or absence 


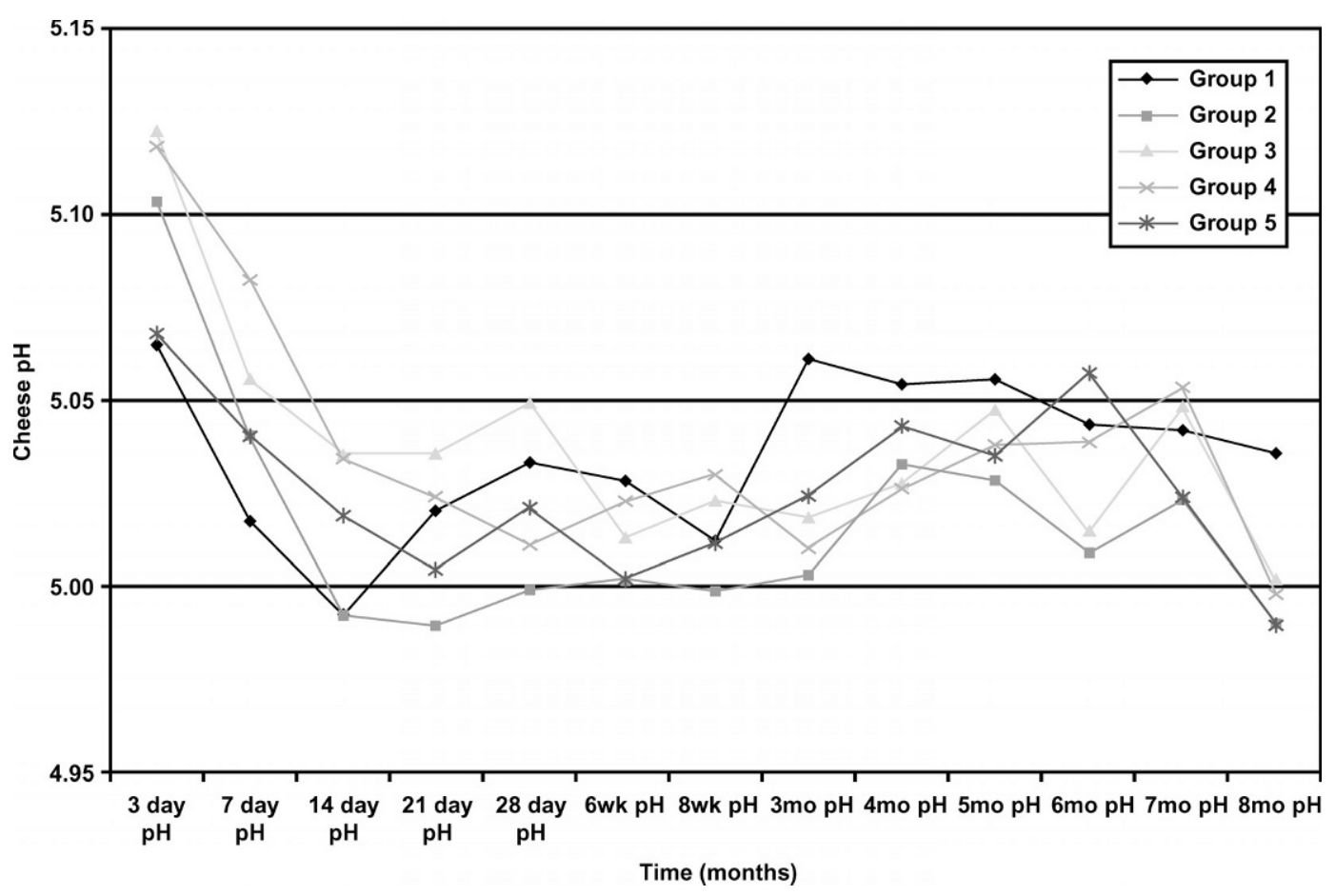

Figure 2. $\mathrm{pH}$ changes in commercial cheddar during curing ${ }^{1,2,3,4}$. Each point is an average of 15 to 20 vats. A total of 97 vats of cheese were tested. Groups $1,2,3,4,5$ are starter culture groups used in the manufacture of cheese tested in this study. $\mathrm{pH}$ profile is a result of cheese tested from one manufacturing facility.

of either defect studied. However, when cheese was sorted by starter group used to manufacture the cheese, a high correlation was observed. Two to 6 vats of cheese were made with each starter group and only the use of starter group 3 resulted in defect free cheese.

Table 3 summarizes the defect rate by starter group for mild and sharp Cheddar. The mild Cheddar data shows that all culture groups, with the exception of group 3, developed some level of defect during their shelf life (42 to 69\%). The same pattern was observed at the end of shelf life for the aged or sharp Cheddar cheese. The sharp Cheddar cheese data showed that the incidence of defects within each starter group varied, but most importantly, use of starter culture group 3 resulted again in cheese that did not manifest either calcium lactate formation or weeping. The defect rate by starter group for sharp Cheddar showed that all other culture groups developed some level of defect during their shelf life (74 to 100\%).

The percentage of packaged cheese showing defects in starter culture groups $1,2,4$, and 5 appeared to be more severe in aged cheese as compared to the cheese from the same vats that were packaged as mild Cheddar 7 mo earlier. This strongly suggests that the choice of starter culture group strongly influenced the appearance of calcium lactate crystals formation and weeping in Cheddar cheese.
Several exceptions are noted in Table 2, where starter groups showed defect rates ranging from 0 to $100 \%$ within the same starter group. This may be explained by multiple strains, within a single starter group, growing disproportionately during preparation of starter batch, prior to use in cheese manufacture. This would lend to variability of strain populations within starter batches leading to strain population variation in cheese.

\section{Cheese Chemistry: Ripening and Shelf Life in Retail Package}

Calcium and soluble calcium. Table 4 shows that the data collected for total calcium on both mild and sharp cheese at 6 mo and at the end of shelf life was not statistically different between the groups with and without the defects. Soluble calcium, however, was statistically significant in mild and sharp cheeses at the time of packaging between the defect and defect free groups. Cheese packaged as mild that would exhibit defects by the end of retail shelf life always demonstrated higher soluble calcium levels. While in aged cheese, by the end of the shelf life (14 mo after manufacture), when the greatest level of calcium lactate was present on the aged cheese surfaces, the soluble 
Table 2. Selection criteria for retail packaged cheese shelf-life evaluation based upon cheese $\mathrm{pH}$ (from 3 and $7 \mathrm{~d}$ ). Includes defect rate at the completion of 6-mo retail packaged shelf life.

\begin{tabular}{|c|c|c|c|c|c|c|c|}
\hline $\begin{array}{l}\text { Starter } \\
\text { culture } \\
\text { used }^{2}\end{array}$ & Production day & Vat \# & $3-\mathrm{d} \mathrm{pH}$ & 7-d pH & Change & $\begin{array}{l}\text { Mild cheese } \\
\text { defect rate }(\%)^{1}\end{array}$ & $\begin{array}{l}\text { Sharp cheese } \\
\text { defect rate }(\%)^{1}\end{array}$ \\
\hline G3 & 22-Mar & 25 & 5.21 & 4.96 & -0.25 & $0 \%$ & $0 \%$ \\
\hline G2 & 12-Mar & 9 & 5.17 & 4.99 & -0.18 & $97 \%$ & $67 \%$ \\
\hline G3 & 22-Mar & 40 & 5.12 & 5.00 & -0.12 & $0 \%$ & $0 \%$ \\
\hline G2 & 2-Apr & 27 & 5.09 & 4.97 & -0.12 & $87 \%$ & $100 \%$ \\
\hline G2 & 2-Apr & 50 & 5.17 & 5.06 & -0.11 & $0 \%$ & $23 \%$ \\
\hline G2 & 9-Apr & 26 & 5.09 & 4.99 & -0.1 & $77 \%$ & $100 \%$ \\
\hline G2 & 30-Mar & 6 & 5.11 & 5.01 & -0.1 & $94 \%$ & $100 \%$ \\
\hline G5 & 11-Apr & 6 & 5.05 & 4.98 & -0.07 & $39 \%$ & $97 \%$ \\
\hline G3 & 2-Apr & 9 & 5.15 & 5.11 & -0.04 & $0 \%$ & $0 \%$ \\
\hline G1 & 3-Apr & 23 & 5.02 & 4.98 & -0.04 & $64 \%$ & $100 \%$ \\
\hline G3 & 26-Mar & 7 & 5.20 & 5.18 & -0.02 & $0 \%$ & $0 \%$ \\
\hline G3 & 10-Mar & 20 & 5.04 & 5.02 & -0.02 & $0 \%$ & $0 \%$ \\
\hline G5 & 17-Mar & 49 & 5.16 & 5.14 & -0.02 & $0 \%$ & $100 \%$ \\
\hline G4 & 12-Mar & 33 & 5.08 & 5.09 & 0.01 & $36 \%$ & $100 \%$ \\
\hline G5 & 10-Mar & 2 & 4.96 & 4.98 & 0.02 & $97 \%$ & $100 \%$ \\
\hline G5 & 7-Apr & 49 & 5.13 & 5.07 & 0.06 & $67 \%$ & $100 \%$ \\
\hline G4 & 16-Apr & 27 & 5.14 & 5.07 & 0.07 & $47 \%$ & $100 \%$ \\
\hline G1 & 13-Mar & 18 & 4.98 & 5.05 & 0.07 & $19 \%$ & $47 \%$ \\
\hline G2 & 16-Apr & 4 & 5.18 & 5.07 & 0.11 & $47 \%$ & $100 \%$ \\
\hline G5 & 13-Mar & 21 & 4.96 & 5.07 & 0.11 & $30 \%$ & $100 \%$ \\
\hline
\end{tabular}

${ }^{1}$ Defect rate at end of shelf-life based upon percentage of 8-oz packages from each 40-lb block showing defect of either calcium lactate or weeping (approximately 75 to 80 pieces).

${ }^{2}$ Starter culture group used in the manufacture of the cheese studied.

calcium level between defect and defect-free cheeses level was not statistically significant.

Lactic acid. No significant difference in the levels of either $\mathrm{D}(-)$ - or $\mathrm{L}(+)$ - Lactic acid was observed between the defect and defect-free groups at 1 mo during this study (Table 4). The level of L(+)-lactic acid did increase over time and by the end of shelf life, significant differences were observed between the defect and defect-free groups for both the mild $(P<0.0002)$ and aged $(P<0.0069)$ cheeses. This suggests that controlling the lactic acid levels at manufacture alone will not prevent calcium lactate crystal formation on cheese. However, it also suggests that as lactic acid levels increase over time, the propensity to develop the defects will increase.

Table 3. Defect rate by starter group at the completioin of 6-mo shelf life.

\begin{tabular}{lcc}
\hline Starter group & $\begin{array}{l}\text { Mild defect } \\
\text { rate }^{1}\end{array}$ & $\begin{array}{l}\text { Sharp defect } \\
\text { rate }^{1}\end{array}$ \\
\hline Group 1 & $42 \%$ & $74 \%$ \\
Group 2 & $69 \%$ & $82 \%$ \\
Group 3 & $0 \%$ & $0 \%$ \\
Group 4 & $42 \%$ & $100 \%$ \\
Group 5 & $47 \%$ & $79 \%$ \\
\hline
\end{tabular}

${ }^{1}$ Defect rate of end of shelf life based upon percentage of 8-oz packages from each starter group showing defect of either calcium lactate or weeping. Packages of cheese were obtained from 18.14-kg (40-lb) Cheddar blocks produced over several production days with each starter group.
$\mathrm{D}(-)$-Lactic acid was found to be less than $0.04 \%$ throughout this study, accounting for $<1 \%$ of the total lactic acid in the cheese tested. The data show that microbial activity resulting in the conversion of $\mathrm{L}(+)$ lactic acid to $\mathrm{D}(-)$-lactic acid and the resulting reduced solubility did not play a part in the appearance of either calcium lactate or weeping defects. Variations in residual lactose levels in the cheeses made with different starter culture groups was not measured and, in retrospect, may have provided valuable information as to why lactic acid levels increased in some cheese over time.

Nonprotein nitrogen. As expected, NPN levels increased during curing. This is a result of the generation of soluble peptides and amino acids from the degradation of primary protein and polypeptides during proteolysis. Neither the mild nor sharp cheeses showed any statistically significant differences between the defect and defect-free groups with respect to levels of NPN (Table 4). The significance of these data may be that protein degradation is not the first step in the release of soluble calcium into the serum.

Salt, moisture, salt in moisture. The data shows that salt, moisture, and salt in moisture $(\mathbf{S} / \mathbf{M})$ are significant in the development of the cheese defects (Table 4). The average S/M for mild cheese exhibiting the defects was $4.19 \%$, while the defect-free cheese was $4.55 \%$. A similar pattern was also observed in the aged category, with the defect cheese having an 
SWEARINGEN ET AL.

Table 4. Chemistry results for mild and aged cheddar cheeses.

\begin{tabular}{|c|c|c|c|c|c|c|}
\hline \multirow[b]{2}{*}{$\begin{array}{l}\text { Chemistry tests } \\
\text { performed }^{1}\end{array}$} & \multicolumn{3}{|c|}{ Mild cheese } & \multicolumn{3}{|c|}{ Aged cheese } \\
\hline & Defect & $\begin{array}{l}\text { Defect- } \\
\text { free }\end{array}$ & $P$-value & Defect & $\begin{array}{l}\text { Defect- } \\
\text { free }\end{array}$ & $P$-value \\
\hline Calcium (in mg/100 g) & 704 & 689 & 0.2188 & 667 & 651 & 0.064 \\
\hline $\begin{array}{l}\text { Soluble calcium at begin of } \\
\text { shelf life (in } \mathrm{mg} / 100 \mathrm{~g} \text { cheese) }\end{array}$ & 440 & 404 & 0.0422 & 419 & 397 & 0.047 \\
\hline $\begin{array}{l}\text { Soluble calcium at end of } \\
\text { shelf life (in } \mathrm{mg} / 100 \mathrm{~g} \text { cheese) }\end{array}$ & 421 & 399 & 0.0293 & 411 & 405 & 0.418 \\
\hline Lactic acid at 1 mo (in $\%$ ) & 1.30 & 1.21 & 0.269 & 1.30 & 1.21 & 0.269 \\
\hline $\begin{array}{l}\text { Lactic acid at end of shelf life } \\
\text { (in \%) }\end{array}$ & 1.523 & 1.353 & 0.0002 & 1.454 & 1.368 & 0.0069 \\
\hline NPN at packaging & 2.07 & 2.09 & 0.4089 & 2.04 & 2.09 & 0.327 \\
\hline NPN at end of shelf life & 2.56 & 2.57 & 0.4822 & 2.52 & 2.57 & 0.379 \\
\hline Moisture (in \%) & 37.52 & 36.88 & 0.0325 & 36.91 & 37.42 & 0.041 \\
\hline Salt (in \%) & 1.58 & 1.65 & 0.0434 & 1.50 & 1.58 & 0.041 \\
\hline Salt in moisture (\%) & 4.19 & 4.55 & 0.0079 & 4.22 & 4.55 & 0.018 \\
\hline Mill pH & 5.37 & 5.41 & 0.100 & 5.42 & 5.38 & 0.069 \\
\hline $\mathrm{pH}$ at $3 \mathrm{~d}$ & 5.07 & 5.15 & 0.009 & 5.09 & 5.13 & 0.112 \\
\hline $\mathrm{pH}$ at $7 \mathrm{~d}$ & 5.02 & 5.07 & 0.048 & 5.03 & 5.06 & 0.170 \\
\hline $\mathrm{pH}$ at $28 \mathrm{~d}$ & 5.02 & 5.08 & 0.020 & 5.02 & 5.08 & 0.016 \\
\hline $\mathrm{pH}$ at packaging 2,3 & 4.99 & 5.05 & 0.061 & 5.00 & 5.06 & 0.030 \\
\hline $\mathrm{pH}$ at end of shelf-life & 5.00 & 5.05 & 0.022 & 5.00 & 5.10 & 0.005 \\
\hline
\end{tabular}

${ }^{1}$ Data are expressed as an average of all samples tested for each category.

${ }^{2}$ Mild was packaged at approximately 6 wk cure and data obtained from initial $\mathrm{pH}$ study at 6 wk.

${ }^{3}$ Aged Cheddar data obtained at time of packaging, approximately 8 mo from date of manufacture.

average $\mathrm{S} / \mathrm{M}$ of $4.22 \%$ and the defect-free cheese with an average of $4.55 \%$. The $\mathrm{S} / \mathrm{M}$ data suggest a possible control mechanism for preventing the defects. Examination of S/M data from individual vats of Cheddar shows that defect-free cheese $(4.30$ to $4.90 \%$, mean $4.55 \%$ ) overlaps across the entire range of cheese with the defect (3.81 to $4.85 \%$, mean $4.22 \%$ ). Furthermore, 6 of 14 defective vats had a S/M above $4.30 \%$. This suggests that although statistically significant, controlling $\mathrm{S} / \mathrm{M}$ in a range above $4.30 \%$ alone would not prevent the development of the defects.

Cheese pH. The effect of cheese $\mathrm{pH}$ in our study is shown in Table 4 . Cheese $\mathrm{pH}$ at mill did not correlate with the appearance of either calcium lactate or weeping in the mild or sharp cheese in this study $(P>0.05)$. The observed $\mathrm{pH}$ drop weeks and months after the cheese was manufactured corresponds well with increases in the level of lactic acid. In addition, soluble calcium levels were higher $(P<0.05)$ in cheese exhibiting defects (calcium lactate or weeping), which coincided with lower cheese $\mathrm{pH}$ (and higher lactic acid) as compared to defect-free cheese. Based upon our data, it appears it is not possible to control the weeping defect or the formation of calcium lactate by strictly controlling target $\mathrm{pH}$ values during the manufacturing of the cheese. Most importantly though, cheese $\mathrm{pH}$ drops below 5.00, postmanufacture, dramatically increases incidence of the defects, as does a $\mathrm{pH}$ drop below 4.96 within the first 6 wk postmanufacturing.

\section{DISCUSSION}

The objective of this work was to determine the effect of cheese $\mathrm{pH}$ change within the first week of curing on calcium lactate defect formation in that cheese. During the study, a second defect, expulsion of liquid, or weeping, became a pronounced defect observed in the cheeses tested and was difficult to separate from the calcium lactate defect. Weeping generally preceded the appearance of calcium lactate crystals on cheese.

Cheese $\mathrm{pH}$, within the first week ( 3 to $7 \mathrm{~d}$ ), did not have an impact on the appearance of calcium lactate or weeping. In fact, many of the factors measured in early manufacturing and curing (less than $7 \mathrm{~d}$ ) such as cheese $\mathrm{pH}$ at mill, lactic acid concentration, NPN, and calcium (total and soluble) did not correlate with the later appearance of either calcium lactate or liquid expulsion. Instead, surprisingly, starter culture used to manufacture the cheese was the most highly correlated measured factor in the study. It appeared that the levels of lactic acid produced by these organisms correlated with cheese $\mathrm{pH}$. This would have affected calcium partitioning between intact cheese paracasein (colloidal) and the free-state or serum (soluble) as reported by Guo et al. (1997) and observed in the first study of this paper. In addition, an increase in soluble calcium, a reactant in the calcium lactate equilibrium reaction was observed in cheese serum. 
The weeping defects observed in this research appear to be linked to the excessive decreases in cheese $\mathrm{pH}$ during curing and retail shelf life. Work by Hooydonk et al. (1988) has shown casein solvation (physically entrapped and nonsolvent water, in grams of $\mathrm{H}_{2} \mathrm{O}$ per gram of casein) decreases as the $\mathrm{pH}$ drops in renneted skim milk, particularly in the range of cheese manufacture and cure. The work showed that maximum water-holding capacity of renneted casein was at approximately $\mathrm{pH}$ 5.3. The excessive $\mathrm{pH}$ reductions observed in cheese likely resulted in a reduction in colloidal calcium beyond critical limits, that left paracasein (paracaseinate-complex) with a significant loss in ability to hold moisture.

The calcium lactate defect observed is thought to be related to the weeping defect. The serum that is expelled during weeping has a high concentration of calcium and lactic acid, well above the saturation point for $\mathrm{L}(+)$-calcium lactate (3.44 $\mathrm{g}$ of calcium lactate per 100 gram of water at $4^{\circ} \mathrm{C}$ or 4.18 gram-calcium lactate per 100 gram of water at $10^{\circ} \mathrm{C}$, both at pH 5.00 (Kubantseva, Hartel, and Swearingen, unpublished data) and if the optimal conditions are present, crystals will develop and grow. This would explain the difficulty is separating weeping and calcium lactate defects in cheeses, as noted in this paper.

Crystal formation will also be contingent upon the existence of nucleation sites. Rough surfaces created during cheese block cutting create crevices that give a lower energy requirement for crystal development to occur (Hartel, 2001). In addition, folds or ends of the cheese pieces, where no direct contact with packaging film occurs, are frequently the location where crystal form first (unpublished data).

The S/M phase was shown to be a possible control mechanism for preventing the defects discussed in this paper. Salt in the moisture will play some role in controlling starter culture fermentation activity and possibly the activity of the nonstarter bacteria. In addition, according to Guo et al. (1997), salt promotes the water-binding capability of paracasein, increasing a cheeses ability to hold moisture. This supports our findings where defect-free cheese had, on average, a higher salt level than defective cheese.

Starter cultures alone will not prevent or eliminate calcium lactate or weeping. Diligence with regard to good cheese manufacture practices will be critical, including minimizing residual lactose and controlling nonstarter lactic acid bacteria that readily drive $\mathrm{pH}$ reduction during curing. In addition, starter culture selection will likely be specific to each cheese manufacturer. Additional work should be completed to understand the specific phenotypic characteristics that starter cultures exhibit that contribute to the defects discussed in this study.

\section{CONCLUSION}

Cheese $\mathrm{pH}$, within the first week ( 3 to $7 \mathrm{~d}$ ), did not have an impact on the appearance of calcium lactate or weeping. Instead, starter culture used to manufacture the cheese was the most highly correlated measured factor in the study. One starter culture group used in the manufacture of the cheese showing the least affect on cheese $\mathrm{pH}$ in the first month post-manufacture and during curing, showed no incidence of calcium lactate crystal formation and weeping during storage and shelf-life. Combining the findings from previous researchers and the results of this study, there is evidence that calcium lactate and weeping defects in Cheddar cheese are caused by postmanufacture fermentation that results in increased calcium and lactate ions in the cheese serum and a reduced water binding capacity of the paracasein.

\section{ACKNOWLEDGMENTS}

We would like to thank the Dairy Management Inc. and Land O'Lakes, Inc. for funding this research. We would also like to express our deep gratitude to Dr. C. Schroeder, Dr. K. Anand, and Dr. Howard Morris for reviewing/editing this paper.

\section{REFERENCES}

Curley, D. M., T. F. Kumosinski, J. J. Unruh, and H. M. Farrell, Jr. 1998. Changes in the secondary structure of bovine casein by Fourier transform infrared spectroscopy: Effects of calcium and temperature. J. Dairy Sci. 81:3154-3162.

Czulak, J., J. Conochie, B. J. Sutherland, and H. J. M. Van Leeuwen. 1969. Lactose, lactic acid and mineral equilibria in Cheddar cheese manufacture. J. Dairy Res. 36:93-101.

Dybing, S. T., J. A. Weigand, S. A. Brudvig, E. A. Haung, and R.C. Chandan. 1988. Effect of processing variables on the formation of calcium lactate crystals on Cheddar Cheese. J. Dairy Sci. 71:1701-1710.

Guo, M. R., J. A. Gilmore, and P. S. Kindstedt. 1997. Effect of sodium chloride on the serum phase of Mozzarella cheese. J. Dairy Sci. 80:3092-3098.

Hartel, R. W. 2001. Crystallization in Foods. Aspen Publish. Gaithersburg, MD.

Johnson, M. E., B. A. Riesterer, C. Chen, B. Tricomi, and N. F. Olson. 1990. Effect of packaging and storage conditions on calcium lactate crystallization on the surface of Cheddar cheese. J. Dairy Sci. 73:3033-3041.

Johnson, M. E., B. A. Riesterer, and N. F. Olson. 1990. Influence of nonstarter bacteria on calcium lactate crystallization on the surface of Cheddar cheese. J. Dairy Sci. 73:1145-1149.

Kindstedt, P. S., and M. R. Guo. 1998. A physico-chemical approach to the structure and function of mozzarella cheese. Aust. J. Dairy Technol. Vol. 53:70-73.

Marshall, T. R., ed. 1993. Standard Methods for Examination of Dairy Products. 16th ed. Am. Publ. Health Assoc., Inc., Washington, DC.

Morris, H. A., C. Holt, B. E. Brooker, J. M. Banks, and W. Manson. 1988. Inorganic constituents of cheese: Analysis of juice from a 
one-month-old Cheddar cheese and the use of light and electron microscopy to characterize the crystalline phases. J. Dairy Res. $55: 255-268$

Official Methods of Analysis, AOAC International, 17th Edition, Method number 984.27, Minerals in Ready-to-feed Milk Based Infant Formula 50:17-18.

Olson, N. F., and M. E. Johnson. 1989. Controlling calcium lactate crystallization. WMMB Res. Rev. 1:1-4.

Pearce, K. N., L. K. Creamer, and J. Gilles. 1973. Calcium lactate deposits on rindless Cheddar cheese. N.Z. J. Dairy Sci. Technol. $8: 3-7$.
Ramkumar, C., L. K. Creamer, K.A. Johnston, and R. J. Bennett. 1997. Effect of $\mathrm{pH}$ and time on the quantity of readily available water within fresh cheese curd. J. Dairy Res. 64:123-134.

Thomas, T. D., and V. L. Crow. 1983. Mechanism of D(-) lactic acid formation in cheddar cheese. N.Z. J. Dairy Sci. Technol.18:131-141.

van Hooydonk, A. C. M., H. G. Hagedoorn, and I. J. Boerrigter. 1986. $\mathrm{pH}$-induced physico-chemical changes of casein micelles in milk and their effect on renneting. 1. Effect of acidification on physico-chemical properties. Neth. Milk Dairy J. 40:281-296. 